\title{
Capsule Commentary on Hsien et al., "Getting Everyone on the Same Page": Interprofessional Team Training to Develop Shared Mental Models on Interprofessional Rounds
}

\author{
Mark Earnest, MD, PhD \\ Division of General Internal Medicine, University of Colorado School of Medicine, Aurora, CO, USA.
}

J Gen Intern Med 35(3):981

DOI: $10.1007 / \mathrm{s} 11606-019-05380-1$

(c) Society of General Internal Medicine 2019

$\mathrm{T}$ his randomized controlled trial by Hsien et al. compared the effect of three team training modalities on the development of shared mental models used in interprofessional rounds. ${ }^{1}$ The first arm received a didactic-only training on specific cognitive tools that could be used in interprofessional rounds. The second arm received the didactic training and a virtual simulation. The third arm received no intervention at all. Team performance measured through full-scale simulation was the main outcome with interprofessional attitudes as a secondary measure.

The full intervention group significantly outperformed the control group in team performance while there was no difference between the didactic only and the control groups, or the didactic only and the full-intervention groups. Both intervention groups showed significant changes in attitudes compared with controls but not compared with each other.

The burgeoning literature in interprofessional education (IPE) has to date relied too heavily on attitudinal outcomes. ${ }^{2}$ The authors' use of a rigorous, behaviorally anchored evaluation strategy is refreshing and commendable. The authors have also published one of the first clear demonstrations of the effectiveness of virtual simulation in changing the behavior of interprofessional learners. This is a significant contribution as many IPE programs struggle to overcome the logistical and fiscal challenges of connecting their learners in face-toface sessions. ${ }^{3}$

The study was not a clear win for virtual simulation as it was not superior to didactic only training when compared directly and the outcomes of interest were measured in the near term only. Future studies would benefit from a longitudinal design to see if the behavior changes proved durable and additional work to improve the discriminatory capacity of the team performance scale.

For interprofessional educators and educational researchers, this study provides an example of a curricular innovation that may solve a number of logistical challenges and an evaluation strategy that could demonstrate that such training may ultimately impact patient care - which is the point after all.

Corresponding Author: Mark Earnest, $M D, P h D$; Division of General Internal MedicineUniversity of Colorado School of Medicine, Aurora, CO, USA (e-mail: Mark.earnest@cuanschutz.edu).

\section{Compliance with Ethical Standards:}

Conflict of Interest: The author declares that he does not have a conflict of interest.

\section{REFERENCES}

1. Hsien L, Chow YL, Ringsted C, Lau TC, Lim WS, "Getting everyone on the same page": Interprofessional team training to develop shared mental models on interprofessional rounds. JGIM (https://doi.org/10.1007/ s11606-019-05320-z).

2. The Institute of Medicine. 2015. Measuring the Impact of Interprofessional Education on Collaborative Practice and Patient Outcomes. Washington, DC: The National Academies Press.

3. Curran VR, Deacon DR, Fleet L, Academic administrators attitudes towards Interprofessional education in Canadian schools of health professional education. J Interprof Care. 2005 1:76-86

Publisher's Note Springer Nature remains neutral with regard to jurisdictional claims in published maps and institutional affiliations. 